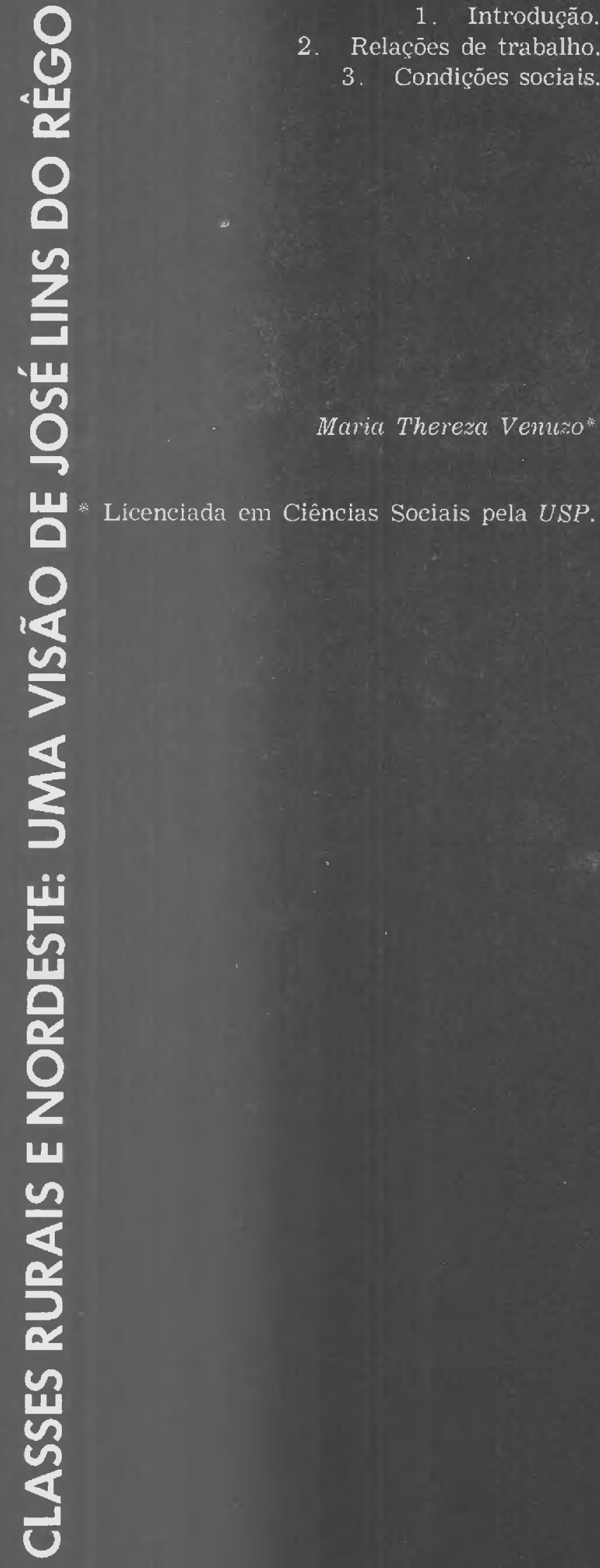

O aparecimento de $A$ bagaceira de José Américo de Almeida, em 1928, marca o reinicio do romance social do Nordeste, numa aparente continuidade da temática do Romance do Norte. Franklin Távora, Manoel de Oliveira Paiva e outros escritores menores já tinham, entre 1880 e 1900, publicado obras que levantam problemas do cangaço, do latifündio, etc. No entanto, as análises agoraca são mais complexas; nāo contém apenas elementos exóticos, mas procuram analisar a sociedade como um todo ou parte desta sociedade. O mundo do cacau (Jorge Amado), ou do açucar (José Lins do Rêgo), ou da migração rural (Amando Fontes), etc., aparecem analisados com um caráter intencional.

Memória e ficção surgem como traços dominantes desta expressāo: a visão de um Jorge A mado ou de um José Lins do Rêgo reproduz, na maior parte das vezes, suas vivências passadas. O segundo deles confessa na sua autobiografia Mens verdes anos - a ligação entre memória e literatura, o que nos leva a verificar a importância e o sentido de sua experiência. Tanto o Ciclo da cana-de-açucar, como seus outros romances do Nordeste, sâo praticamente retratos fiéis de uma realidade, vista através da sua sensibilidade literária e humana.

Sabemos que para uma utilização válida da obra literária como conhecimento da realidade é essencial que à estrutura da obra tenha seu sig. nificado próprio e relação com uma realidade social concreta.

A obra pode então ser reconduzida à realidade, e explicada pelos compromissos que tem com o exterior.

Em sua obra do Ciclo da cana-de-açicar, José pressão de uma visāo do mundo coincide com o meio em que o escritor esteve em contato imediato durante uma parte considerável de sua vida.

Em sua obra do Ciclo da cana-de-açicar, José Lins do Rêgo retrata um universo concreto de seres e de coisas. A partir da sua maneira de ver e sentir este univer'so, ele encontrou a forma adequada para criar e expressar esse mesmo universo. Sua criaçāo literária coincide com o conjunto do processo e da evoluçāo histórica brasileira, na medida em que coloca os problemas mais gerais da época: o latifundio, as relaçōes de trabalho, as relaçōes sociais na estrutura agrária do açúcar.

Não pretendemos mostrar neste trabalho o aspecto literário ou autobiográfico da obra do paraibano José Lins do Rêgo, mas as relaçōes de trabalho e as condições sociais de existência nos

R. Adn. Emp.

Rio de Janeiro 
engenhos de açúcar, tal como são descritas em sua obra.

Aproveitamos a reprodução que o autor faz de ambientes e de individuos, homens determinados pelas circunstâncias exteriores, notadamente pelo ambiente em que vivem, e adaptados ao pequeno mundo do engenho, que é sua realidade imediata.

Deixamos de lado, propositadamente, duas obras que se encontram intrinsecamente ligadas ao assunto - Fogo morto (1943) e Meus verdes anos (1956) - porque achamos que seus primeiros romances levantam com muita clareza os elementos essenciais que objetivam nossa análise. Assim, utilizamo-nos somente dos romances do Ciclo da cana-de-açicar, isto é, Menino de engenho (1932), Doidinho (1933), Bangüê (1934), Moleque Ricardo (1935) e Usina (1936).

Esses livros descrevem um processo de produção geral do Nordeste, isto é, a cultura do açúcar. A ação situa-se numa época em que a antiga propriedade do engenho vai deixando de existir, sendo gradativamente superada pelo sistema moderno da usina. A trama passa-se especificamente na Paraiba e Pernambuco, entre fins do século XIX e início da década de 20. A localização dos problemas no espaço e no tempo permite-nos uma visão mais real do seu mundo. Porém, como pretendemos somente analisar uma parte do meio rural - o engenho - deixamos de lado todas as questōes referentes à usina e também à problemática urbana que se desenrola em Cabedelo e no Recife.

Após a Abolição da Escravatura, na grande lavoura canavieira do Nordeste, o sistema de propriedade e suas formas de exploração passam por um periodo que se caracteriza pela coexistência de formas antigas e modernas de produção. Isto acontece devido à lentidão do processo de superação dos antigos engenhos. Durante muito tempo, o engenho apresenta condições para resistir a uma forma moderna de economia.

Em pleno século XX, encontramos ainda o en-

126 genho como um pequeno mundo isolado, conservando traços de economia independente, sua tecnologia e suas formas de remuneração do trabalho.

As outras culturas do engenho, de expressão local e de valor econômico mínimo existem para fazer predominar o sistema de exploração da grande mão-de-obra ocupada com a produção açucareira, a mais lucrativa de todas as formas agricolas existentes. A concentração de grande massa de trabalhadores numa unidade produtora cria um sistema típico de organização agrária.

Forma-se um tipo de exploração rural separado da grande lavoura. O senhor de engenho cedendo aos seus servidores o direito de se estabelecerem e explorarem uma parte inaproveitada de seu dominio, exige em troca a prestação de serviços. Desenvolvem-se, então, relações entre o proprietário e os trabalhadores sem terra, em decorrência do sistema de exploração da terra e das condições do meio natural.

Do tipo de organização da lavoura e do trabalho deriva toda a estrutura do engenho: a disposição das categorias sociais de sua população, isto é, o conjunto das relações sociais.

Delimitado o nosso campo, vejamos os problemas como se apresentam. Para isto, achamos necessário mostrar, antes de mais nada, a problemática geográfica: numa sociedade agricola, a relação com o meio natural é fundamental. Mesmo que o homem possa agir contra a natureza, modificando certos elementos naturais - irrigação, destruição de matas, etc. - sua vida é regulada pelas estaçōes e pelas condições geográficas gerais. Daí, nossa necessidade de localização do fenômeno estudado e o levantamento deste dado inicial e fundamental.

A ação passa-se no vale do rio Paraíba do Norte e o fator geográfico aparece representado ai, em toda sua complexidade. Aparecem descritos acidentes geográficos típicos, representados no latifúndio de José Paulino. Esses elementos somados dão-nos uma visão conjunta do fenômeno.

O "Santa Rosa", nome do latifúndio de José Paulino, é o resultado da compra de algumas propriedades "hipotecadas aos judeus da Paraiba". Pela sua extensão torna-se uma das maiores benfeitorias da zona. Sua sede e suas atividades açucareiras localizam-se no vale, enquanto outros tipos de atividades se desenvolvem no agreste. Suas terras estendem-se por léguas e léguas de norte a sul. "Tudo o que tinha era para comprar terras e mais terras. Herdara o Santa Rosa pequeno, e fizera dele um reino, rompendo seus limites pela compra de propriedades anexas. Acompanhava o Paraíba com as várzeas extensas e entrava de caatinga adentro. Ia encontrar as divisas de Pernambuco, nos tabuleiros da $\mathrm{Pe}-$ dra de Fogo. Tinha mais de três léguas de estrema a estrema. E não contente de seu engenho, possuía mais oito, comprados com os lucros da cana e do algodão."

Temos, pois, no latifúndio de José Paulino, duas zonas distintas: a várzea e o agreste. Como sabemos, na Paraíba existe uma interligação entre essas zonas, devido ao problema da formação geológica.

Na Paraíba e no Rio Grande do Norte, "a mata propriamente dita é restrita às várzeas dos rios que desaguam no Atlântico, enquanto nas en- 
costas e nos interflúvios plenos que separam as bacias fluviais, dominam as associações vegetais semelhantes, e chamadas localmente de tabuleiros". ${ }^{2}$

Essa caracterização determina atividades agricolas e humanas diversas. Ao problema do solo precisamos acrescentar o do clima e o da água. O clima apresenta duas estações distintas: a das chuvas e a das secas. A delimitação baseada nestes aspectos exteriores é que caracteriza climaticamente a região. O inverno, isto é, a época das precipitações pluviais é o momento do preparo da terra, do plantio, da germinação; a época das secas, isto é, o verão, é o momento da colheita, do fabrico do açúcar, etc. José Lins do Rêgo descreve a natureza como fenômeno telúrico, onde fecundidade da terra e existência humana aparecem interligadas: "a chuva chegava com pingos de furar o chão, e chovia dia e noite sem parar. As primeiras chuvas do ano faziam uma festa no engenho. $O$ tempo armava-se com nuvens pesadas, fazia um calor medonho. (...) 0 meu avô ficava pelo alpendre a contemplar o céu, batendo com a vara de jucá pelas calçadas. Era sua grande alegria: a bátega d'água amolecendo o barro duro dos partidos, a enverdecer a folha amarela das canas novas. Nas primeiras pancadas do inverno, os cabras deixavam o eito para tomar uma bicada na destilação. Vinham gritando de contentes, numa alegria estrepitosa de bichos. Mas isto somente nas primeiras chuvas". ${ }^{3}$

A constância das chuvas pode ser quebrada às vezes por uma grande estiagem. No verão, o rio fica seco, apresentando apenas alguns poços no seu leito para vencer esta estiagem. Ficaram na memória dos personagens secas famosas como a de 1877. Por sua vez, as enchentes excessivas não são constantes, mas algumas também ficaram na história pela destruição que acarretaram.

A base geográfica condiciona todas as formas de cultura material, mas elas só podem ser compreendidas como resultado de um processo histórico anterior, que se desenvolve desde a época colonial. $O$ que interessa a José Lins do Rêgo, nọ entanto, não é o passado, mas sua condição presente.

A determinante geográfica continua a ser preponderante quando o autor descreve o aproveitamento do solo pelo homem: várzea e tabuleiros exigem diversificação das culturas. Como dissemos anteriormente, o. Santa Rosa de José Paulino engloba essas duas áreas e a complexidade de tarefas torna seu latifúndio um exemplo. $O$ plantio do milho, do algodão e o pastoreio aparecem como atividades secundárias, enquanto que a cana é o produto fundamental.
A cana ocupa as melhores terras e absorve a maior parte das atividades humanas. Mais exigente em relação ao solo, ela requer umidade e por isso é cultivada nas várzeas e terrenos mais férteis. $O$ cultivo da cana na várzea também facilita o transporte do produto para os locais da moagem.

Por sua vez, os roçados de algodão de José Paulino eram plantados na caatinga, longe da casa-grande. "Cem sacos de lã arrancava dali, milhares de alqueires de milho, e carros e mais carros de jerimuns vinham para os porcos."

\section{Relações de trabalho}

A diversificação agrícola explica relações de produção específicas: a cana, que é planta permanente, exige concentração de trabalho e técnica mais aperfeiçoada; as culturas dos tabuleiros algodão e milho - que têm a duração de meses, permitem um sistema de trabalho mais simples.

Plantada em junho ou julho, a cana precisa de várias limpas anuais. No tempo da limpa, em cada partido trabalhavam mais ou menos 80 homens, comandados por um feitor, que de cacete na mão, ficava "reparando no serviço deles". Eram doze horas de trabalho pesado. Só paravam às 10 horas da manhã, para almoçar farinha seca com bacalhau e carne-de-ceará assada com farofa.

Esses homens - os trabalhadores de eito são em parte ex-escravos. Têm a obrigatoriedade de trabalhar três dias por semana para José Paulino, ganhando 1200 réis por dia. Nos demais dias podem trabalhar para si próprios, plantando mandioca, jerimuns, batata-doce, etc. Essas lavouras são feitas nas terras férteis das vazantes do rio. Geralmente são as mulheres que trabalham nos roçados, enquanto os homens descansam do trabalho no eito.

A situação é bem pior em outras fazendas da redondeza. Na propriedade do Sr. Lourenço, irmão de José Paulino - Gameleira - localizada nas terras mais pobres da caatinga, os trabalha. dores de eito não têm regalias pessoais e nenhuma plạntação para uso próprio, vivendo somente de suas diárias.

$\mathrm{Na}$ colheita da cana, o engenho começa a produzir açúcar. A "botada", isto é, a época da safra, é o momento de festas, produção e dinheiro. Nessa época, José Paulino não descansa: "montava a cavalo para ver o corte, gritava para os carreiros, para o maquinista, mandava recados para o mestre-de-açúcar, para os caldeireiros. (...) No outro dia, quando o engenho apitasse às três horas da madrugada, ele estaria lá. Era o primeiro que chegava. E à noite só deixava o 
serviço quando batiam a última têmpera"."

O processo de fabricação de açúcar é muito rudimentar e assemelha-se à experiência do passado, o que explica a pouca produtividade e a má qualidade do produto. "Ficava a fábrica bem perto da casa-grande. Um enorme edificio de telhado baixo, com quatro biqueiras e um bueiro branco, a boca cortada em diagonal. (...) Voltei-me inteiro para a máquina, para as duas bolas giratórias do regulador. Depois comecei a ver os picadeiros atulhados de feixes de cana, o pessoal da casa de caldeiras. Tio Juca começou a me mostrar como se fazia o açúcar. O Mestre Cândido com uma cuia de água de cal deitando nas tachas e as tachas fervendo, o cocho com o caldo frio e uma fumaça cheirosa entrando pela boca da gente. [Na casa de purgar] dois homens levavam caçambas com mel batido para as formas estendidas em. andaimes com furos. Ali mandava o purgador, um preto, com as mãos metidas em lama suja que cobria a boca das formas. Meu tio explicava como aquele barro preto fazia o açúcar branco. $E$ os tanques de mel-de-furo com sapos ressequidos por cima de uma borra amarela, me deixaram uma impressão de nojo."6 Como vemos, José Lins do Rêgo apresenta todos os elementos humanos da estrutura agrícola do açúcar: trabalhadores de eito e feitores são responsáveis pelo sistema de plantio, limpa e corte; cambiteiros e carreiros transportam a cana para o engenho. Depois temos o maquinista, o mestrede-açicar e os caldeireiros, que são trabalhadores especializados, encarregados do fabrico do açúcar.

Diferente do processo da cana são as atividades no agreste. Como já dissemos, nesta área as formas de trabalho são mais simples porque as possibilidades de seu solo são mais limitadas. Ali se cultivam produtos que, pelo seu valor menor, estão entregues a intermediários, como os foreiros e meeiros. Estes trabalham com toda a família nos seus roçados. Não têm obrigação de dar três dias por semana no eito. Os foreiros pagam o foro anualmente e vivem de seus roçados de fava ou de algodão, plantados no agreste. No entanto, são obrigados a vender no engenho o que colhem. Caso contrário, o senhor ameaça soltar o gado nas suas plantações. Já os meeiros plan. tam cana às suas próprias custas, e se comprometem a dar metade da produção ao senhor de engenho na moagem. Utilizam a terra e a máquina do engenho; o senhor despende apenas com a mão-de-obra para o fabrico do açúcar.

\section{Condições Sociais}

Encontramos nos dois tipos de cultura - várzea e agreste - uma divisão social nitida entre trabalhadores e proprietários: o senhor e seus dependentes aparecem como elementos principais do processo agrícola. Os trabalhadores de eito não estão no mesmo nivel dos operários especializados, dos meeiros e foreiros. Seus salários e condiçōes de vida são inferiores. Entretanto, a dependência em relação ao sistema de propriedade identifica os trabalhadores de eito com as outras categorias. Apesar da capacidade técnica e de condiçōes de trabalho distintas de cada um deles resultarem em regalias diferentes, a condição comum a todos é a de subordinação ao senhor. Dai podermos dizer que existem escalas diferentes entre essas categorias, que são somente quantitativas e nunca qualitativas.

A condição de vida dos trabalhadores de eito está socialmente determinada pela sua condição de trabalho, inferior a de todas as outras categorias: "Nós, os da casa-grande, estávamos ali reunidos no mesmo medo, com aquela pobre gente do eito. $\mathrm{E}$ com eles bebemos o mesmo café com açúcar bruto e comemos a mesma batata-doce do velho Amâncio. $\mathbf{E}$ almoçamos com ele a boa carne-de-ceará com farofa. A noite dormimos em cama de vara. A chuva pingava dentro de casa por não sei quantas goteiras. $\mathrm{E}$ o cheiro horrivel dos chiqueiros de porcos pertinho da gente. (...) Era tudo isto o que de melhor o pobre do velho Amâncio tinha para nos oferecer: esta sua desgraçada e fedorenta miséria de pária."”

Como resquicio do passado, uma parte dos trabalhadores de eito, constituida por ex-escravos, mora na senzala; esta continua a existir pegada à casa-grande, mesmo depois da Abolição, "com as suas negras parindo, as boas amas-de-leite e os bons cabras do eito". ${ }^{8}$

A posição inferior dos trabalhadores de eito torna-se também evidente pelo tratamento que os rendeiros e meeiros dispensam a essa gente. Nas épocas em que os trabalhos de limpa e plan: tio requerem maior número de braços, os rendeiros e meeiros vêm ajudar no eito: "desciam de suas ordens para este contato ombro a ombro com os párias". ${ }^{\circ}$ Prestam esse serviço a José Paulino e nāo aceitam nenhum pagamento por ele, por considerarem indigno o trabalho no eito.

Entretanto, os trabalhadores de eito "pareciam felizes de qualquer forma, muito submissos e muito contentes com o seu destino, ( . .) não levantavam os braços para imprecar, não se revoltavam. Eram uns cordeiros". ${ }^{10}$

José Lins do Rêgo apresenta-nos estes trabalhadores como elementos passivos e acomodados diante do meio em que vivem. Eles não reagem, sua atitude é de completa indiferença. Aqueles 
que têm suas lavouras vestem-se "com as arrobas de algodão que o roçado lhes dava. Se não chegasse, os trapos de brim e de chita passavam de um ano para outro. As filhas se casavam. Matavam galinha no dia da festa. Era uma de menos nas costas. $E$ se não quisessem casar podiam se amigar, que era a mesma coisa".11

A prostituição apresenta-se como meio de ascensão social: é "um elemento de progresso por ali". ${ }^{12}$ As mulheres que são seduzidas pelo senhor do engenho melhoram a vida da familia toda. $O$ pai deixa de trabalhar no eito, e não precisa pagar foro para ter roçado. A familia passa a receber açúcar e outros gêneros do engenho, de graça.

A prostituição aparece, assim, como uma solução temporária e limitada que não disfarça a realidade. A parca remuneração de trabalho aparece como a constante de suas vidas. Só lhes é possivel garantir as condições mínimas para sua sobrevivência.

Temos ainda outra forma de trabalho, o doméstico. Este é realizado na casa-grande pelas ex-escravas e tem todas as características do trabalho servil. A função delas ainda é a mesma: cozinhar, cuidar de crianças, parir os filhos. Depois da Abolição, elas não quiseram deixar o Santa Rosa. Trabalham de graça e José Paulino dálhes de comer e vestir. As filhas e netas das negras também vão continuando na servidão "com a mesma passividade de bons animais domésti$\cos ^{\prime \prime} .^{13}$

José Lins do Rêgo apresenta-nos somente um tipo que não se conforma com a miséria e a baixa condição social. Trata-se do moleque Ricardo, que vai buscar ascensão social fora do mundo rural. O moleque Ricardo se afasta da fazenda, mas volta anos mais tarde para trabalhar como caixeiro no barracão do engenho.

Já os operários especializados, isto é, os mestres-de-oficio, têm algumas regalias no Santa Rosa. Fazem suas refeições na casa-grande, sentados à mesa com o senhor e a família, comèndo a mesma comida. No entanto, não participam das conversas da casa, visto que também sāo pessoas humildes.

Como vimos, os rendeiros e meeiros não estão vinculados definitivamente à terra e o problema da dependência ao senhor de engenho subsiste. O reflexo social da dependência aparece nas relações entre aqueles e este: o senhor não é só aquele que tem e cede suas terras a rendeiros e meeiros mas também o que dá conselhos, é juiz, toma decisões superiores que devem ser obedecidas. $\AA$ tarde, depois do jantar, José Paulino sentava-se "numa cadeira perto do grande banco de madeira do alpendre para dar as suas audiên- cias públicas aos moradores. Era gente que vinha pedir ou enredar. Chegavam sempre de chapéu na mão com um 'Deus guarde a Vossa Senhoria'. Queriam terras para botar roçado, lugar para fazer casas, remédios para os meninos, carta para deixar gente no hospital. Alguns vinham fazer queixa dos vizinhos. (. . .) Muitos vinham arranjar carros do engenho para fazer mudanças, e alguns dar conta de suas meações com o senhor ou pagar o foro do ano. A todos o meu avô ia dando uma resposta ou passando uma descompostura, mas cedendo sempre no que eles pediam". ${ }^{14}$

No Santa Rosa há um meeiro que consegue juntar algum dinheiro e estender suas lavouras, - que constitui uma exceção. Geralmente não há diferenças sensiveis entre as condiçōes materiais dos trabalhadores de eito e as dos meeiros e foreiros. Estes, porém, recebem melhor tratamento, têm formas de trabalho mais livres, e uma certa independência de atitudes. Embora recebam visita da gente da casa-grande, esse contato mais intimo não significa relações de igual para igual, o que não os impede de se sentirem privilegiados.

Descrito o sistema de subordinação, podemos agora estudar a vida e o comportamento dos senhores de engenho.

José Paulino é o grande latifundiário da várzea do Paraiba, mas apesar de sua riqueza, leva uma vida modesta. Não tem "luxo nenhum. A casa-grande só tinha tamanho. Tudo muito pobre: nem uma cadeira bonita, a cama onde dormia era de couro, dura como de frade". Para ele, "houvesse comida com fartura - era o que bastava". ${ }^{15}$ "O velho Zé Paulino, tão sem vaidade para as outras coisas, amava o luxo da bacharelice. (...) ,Percebia-se-lhe a contrariedade em não ver o filho Juca feito juiz de direito ou procurado para defender no júri." 16

O mesmo não se dá com o Coronel Lula, seu primo, que gosta de ostentar sua riqueza. A casagrande de seu engenho é a melhor casa de morada da ribeira do Paraíba. Tem água encanada na horta e banheiro para os criados.

José Paulino também não se interessa pela política: "Depois entravam na conversa de política. O meu avô não concorria na palestra. ( . . ) 0 que mais o interessava eram os bons invernos, 0 seu açúcar na casa de purgar, o seu gado gordo, os seus partidos. Quando lhe vinham perguntar pela política ele mudava de conversa. Estava com o. seu partido por hábito." Ao contrário de outros senhores de engenho, "não tinha cabras para proteger, nem medo de ficar por baixo. $O$ governo como terror, como encosto para tomar terra dos pequenos, governo que the desse soldados para 
guarda-costas, deste governo ele nunca precisou. A sua consciência limpa deixava-o dormir sossegado, sem receio de diligências em suas terras". ${ }^{\text {" }}$ "O velho José Paulino governava os seus engenhos com o coração. (...) Os senhores de engenho iam até às armas, nas disputas. Brigavam pelos seus partidos, profanavam os templos de Deus, arrombando urnas e queimando atas, (...) iam na frente com os seus negros. Mas o velho José Paulino não era homem para tais coisas. Ele era temido mais pela sua bondade. Não havia coragem que levantasse a voz para aquela mansa autoridade de chefe. Não tinha adversários na sua comarca. Os seus inimigos eram mais de sua familia do que dele. Herdara-os com o Santa Rosa." 18

Já o Dr. Lourenço - irmão de José Paulino - é o típo do grande senhor de engenho: "era outra coisa. Tinha gênio, como se dizia dos homens fortes, de coração duro. $E$ por isto foi aquele político, manobrando com dois municipios. A casa se enchia de sujeitos que chegavam para tratar de eleições". ${ }^{19}$

A situação de riqueza e poder, José Lins do Rêgo acrescenta um retrato do comportamento e dos valores dos senhores de engenho, que aparece no seu relacionamento intimo, quando "aos domingos, a mesa da casa-grande se enchia de senhores de engenho, de parentes, de correligionários. (...) Uns contavam grandezas, negócios de vento em popa. Outros choravam de fazer pena. Não faziam nada, não podiam nem pagar aos correspondentes. $E$ eram sempre estes os mais prósperos. Fora da presença do chefe (Dr. Lourenço), pareciam meninos em recreio, bulindo uns com os outros. Queixavam-se sempre dos trabalhadores. Nisto estavam de acordo, em reconhecer nos seus cabras qualidades péssimas. Eram para eles uma gente ruim, preguiçosa, trapaceira, que só prestava mesmo no relho. Passávamos os domingos num instante com as visitas. Vinham em outros dias, mas para negócios, ou para pedir favores, tachas emprestadas, tubos para caldeira, sementes de cana". ${ }^{20}$

Porém, grande número de senhores de engenho estão em completa decadência. $O$ Coronel Lula de Holanda, vizinho de José Paulino, já está de "fogo morto". Seu engenho parou de produzir há muito tempo: "Ao lado da prosperidade e da riqueza do meu avô, eu vira ruir, até no prestígio de sua autoridade, aquele simpático velhinho que era o Coronel Lula de Holanda, com o seu Santa Fé caindo aos pedaços. (...) Não plantava um pé de cana e não pedia um tostão emprestado a ninguém." "21 "O meu avô olhava para o seu vizinho com certo respeito. (...) En- quanto ele crescia, o outro se atrasava naquela miséria que arrastou por mais de $\mathbf{7 0}$ anos. A princípio, o engenho de besta ainda quebrava uns feixes de cana. Fazia uns cem pães. Depois, dera para vender verduras, macaxeira em molhos, para o Pilar. Andava de carro, até que os cavalos morreram"."22

A análise que nos propusemos a fazer termina aqui. Propositadamente, deixamos de estudar outros elementos que aparecem no Ciclo e que estão intrinsecamente ligados ao nosso tema: os problemas da usina e a problemática urbana. José Lins do Rêgo nos dá esses elementos, apesar de termos nos restringido ao mundo rural. A razão é de objetivo, pois achamos que o mundo do engenho descrito pelo escritor apresenta-se com traços de autonomia, o que nos permite estudá-lo isoladamente.

Queremos acentuar no entanto, que autonomia significa aqui um processo que contém elementos distintos, dai podermos delineá-los independentemente. A distinção não nos leva a dizer que o fenômeno do engenho rural não tenha ligações com os dois outros processos, isto é, o da industrialização do açúcar (usina) e o da urbanização.

Porém, a autonomia do engenho demonstranos a persistência de um processo anterior, ainda naquele momento. Como sabemos, as formas de trabalho descritas pelo romancista vêm do Brasil Colônia; no século XIX, o sistema de produção e o sistema de relaçōes de trabalho praticamente não se modificam. A técnica moderna de tratamento do açúcar - usina - é introduzida lentamente nos fins do Império e começo da República: porém, ela supera o sistema arcaico do bangüề somente na década de 30 . Assim, no momento em que José Lins do Rêgo retrata o mundo do Nordeste - 1901-1925 - os dois sistemas persistem um ao lado do outro. Daí o autor descrever-nos um processo, com traços coloniais em pleno século $\mathrm{XX}$.

A análise do bangüê permite-nos distinguir essa permanência de elementos do passado: as formas predominantes do trabalho, semelhantes às da época da escravidão; a produção de açúcar que utiliza a mesma técnica dos séculos anteriores. Por sua vez, a persistência implica formas mais simplificadas, que permitem a continuidade do regime de autonomia do engenho. Como no passado, o latifúndio tem condiçōes próprias de sobrevivência. Trabalhadores braçais e técnicos vivem em função da produção local $e$, o único elemento que líga o latifúndio produtivo - bangüề - com o exterior, é a comercialização do açúcar. José Paulino só sai de suas terras uma vez por ano, na época da venda de sua safra. Por 
outro lado, o latifúndio é auto-suficiente na produção para sua subsistência, dependendo somente de alguns produtos industrializados.

Essa problemática de autonomia é que nos permitiu um estudo do fenômeno do engenho. Utilizamo-nos fartamente da documentação apresentada por José Lins do Rêgo, pois os seus romances retratam admiravelmente um mundo em transição, onde coexistem passado e presente, apesar de alguns elementos já terem começado a diluir-se.

Para uma complementação dos estudos, teríamos necessariamente de nos utilizar de outras fontes históricas em geral. A soma desses estudos dar-nos-ia uma visão mais rica da problemática do Nordeste. $O$ que não podemos esquecer é que a obra de José Lins do Rêgo por si mesma é fundamental para o conhecimento da realidade nordestina.
1 Lins do Rêgo, José. Memino de engenho. Livraria José Olympio Editora, 1960. p. 55. (Romances reunidos e ilustrados de José Lins do Régo.)

2 Andrade, Manoel Correla de. A terra e o homem no Nordeste. 2. ed. Editora Brasiliense, s.d.

a Lins do Rêgo, José. Menino de engenho. cit. p. 81.

4 Lins do Rego, José. Bangüe. p. 253.

5 Id. ibid. p. 252.

- Lins do Régo, José. Menino de engenho. cit. p. 10.

7 Id. ibid. p. 22.

8 Id. ibid. p. 44.

- Id. ibid. p. 66.

10 Id. ibid. p. 22.

11 Lins do Régo, Josê. Bangiüé, cit. p. 307.

12 Id. ibid. p. 342.

13 Lins do Rêgo, José. Menino de engenho. cit. p. 41.

14 Id. ibid. p. 44-5.

15 Lins do Rêgo, José. Bangï̈ê. cit. p. 254.

10 Lins do Régo, José. Doidinho. p. 171.

17 Id. ibid. p. 112.

18 Lins do Rego, José. Menino de engenho. cit. p. 53.

19 Lins do Rêgo, José. Bangüe. cit. p. 334.

20 Id. Ibid. p. 335-6.

21 Lins do Rếgo, Jose. Menino de engenho. cit. p. 56.

22 Lins do Rego, Jose. Bangtie. cit. p. 368.

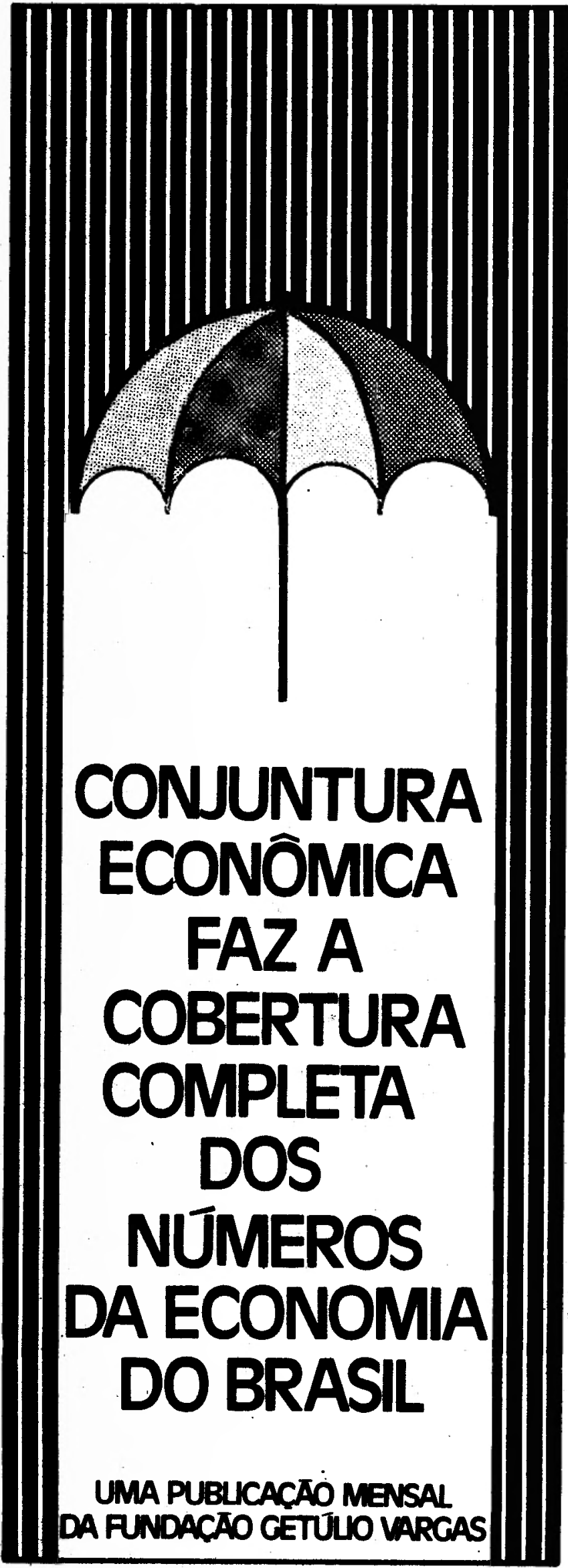

Classes rurais e Nordeste 